\title{
Salivary Cell-Free HSD17B1 and HSPA1A Transcripts as Potential Biomarkers for Estrus Identification in Buffaloes (Bubalus Bubalis)
}

Shubham Singha

National Dairy Research Institute

Rubina K. Baithalu ( $\nabla$ rbaithalu@gmail.com )

National Dairy Research Institute

Mamta Pandey

National Dairy Research Institute

Latika Jaiswal

National Dairy Research Institute

Sangram Dash

National Dairy Research Institute

Abhijeet Fernandes

National Dairy Research Institute

Tushar K. Mohanty

National Dairy Research Institute

A. Kumaresan

National Dairy Research Institute

Biswa Ranjan Maharana

Lala Lajpat Rai University of Veterinary and Animal Sciences

T. Sarath

Madras Veterinary College

\section{Research Article}

Keywords: Buffalo, Cell-free mRNAs, Estrous, qRT-PCR, Saliva

Posted Date: March 7th, 2022

DOI: https://doi.org/10.21203/rs.3.rs-1389469/v1

License: (c) (1) This work is licensed under a Creative Commons Attribution 4.0 International License.

Read Full License 


\section{Abstract}

Background: Estrus detection is a major problem in buffaloes because of the poor expression of estrus signs leading to low reproductive efficiency. Salivary transcripts analysis is a promising tool to identify biomarker; therefore, the present study was carried out to evaluate their potential as estrus biomarker.

Methods: The levels of $H S D 17 B 1, I N H B A, H S P A 1 A$, Testin transcripts were compared in saliva during estrous cycle stages [early proestrus (day $-2, E P$ ), late proestrus (day-1, LP), estrus (E), metestrus (ME) and diestrus $(D E)$ ] of cyclic heifers $(n=8)$ and pluriparoous $(n=8)$ buffaloes by employing quantitative real-time polymerase chain reaction (qRT-PCR).

Results: The levels of HSD17B1 (EP/DE 1.46-2.43 fold, LP/DE 2.49-3.06 fold; E/DE 7.21-11.9-fold P<0.01; ME/D 1.0-1.16 fold) and HSPATA (EP/DE 0.93-2.39 fold, LP/DE 2.68-3.23 fold; E/DE 8.52-15.18 fold $\mathrm{P}<0.01 ; \mathrm{ME} / \mathrm{D}$ 0.86-1.01 fold) were significantly altered during the estrus than other estrous cycle stages in both cyclic heifers and pluriparous buffaloes. Receiver operating characteristic curve analysis revealed ability of salivary HSD17B1 (AUC 0.96; $\mathrm{P}<0.001$ ) and HSPA1A (AUC 0.99; $\mathrm{P}<0.01$ ) to differentiate $\mathrm{E}$ from other stages of estrous cycle.

Conclusion: Significantly higher levels of $H S D 17 B 1$ and HSPA1A transcripts in saliva during estrus phase suggest their biomarkers potential for estrus detection in buffaloes.

\section{Introduction}

Identifying the estrus phase accurately and efficiently is crucial to successful artificial insemination (Al) and conception in farm animals. Nevertheless, the buffalo is considered a shy breeder and the expression of estrus signs are not very prominent, especially during the summer months which leads to a higher incidence of silent estrus (29\%) [1] and beget estrus detection difficult [2]. In addition, the varied estrus detection tools used for estrus detection in cattle aren't very effective in detecting estrus in buffaloes since their sensitivity and specificity vary widely [3]. Therefore, finding an easy, reliable, and accurate method for estrus detection in buffaloes is of utmost importance.

Saliva is preferred to other biological fluids for the discovery of biomarkers as it can be collected in a noninvasive, stress-free and un-stimulated condition [4, 5]. Saliva contains specific biomolecules like mRNA, miRNA, DNA, or protein that reflect the individual's physiology or disease condition [6]. For instance, a lower level of polypeptide 1 (CYP27A7) and sialic acid acetyltransferase (SIAE) transcript in the saliva was found to be associated with oral squamous cell carcinoma (OSCC) in humans (AUC 0.84) [7]. Similarly in humans, the pancreatic disease has been shown to increase the levels of specific transcripts (MBD3L2, KRAS, STIM2, ACRV1, DMD and CABLES1) in saliva [8]. In contrast to humans, salivary transcriptome analysis in farm animals has not been explored. For the first time, our group has reported direct salivary transcript analysis (DSTA) as a novel non-invasive method for estrus detection in buffaloes [9]. The study found that salivary HSP7O and TLR4 levels were higher during estrus than at diestrus during the buffalo estrous cycle. Additionally, DSTA against target miRNAs identified miR-16, 
miR-191, and miR-223 as indicators of dominant ovarian follicles in buffaloes [10]. In a recent study, Hebbar et al. [11] identified urinary cell-free miR-99a-5p as a potential candidate for estrus detection in buffaloes. Their study demonstrated a significantly lower level of miR-99a-5p during estrus and receiveroperating characteristic (ROC) analysis revealed its ability (AUC of $0.64, \mathrm{P}<0.08$ ) to differentiate estrus from the diestrus stage of the estrous cycle. Transcriptomic analysis of goat ovarian tissues showed altered mRNA expression between estrus and diestrus [12]. Since the ovary has a rich blood supply, it seems rational to hypothesize that mRNA may be excreted differentially into the peripheral circulation depending on the stage of the estrous cycle and some of these systemic transcripts may be in saliva as a transudate, which can mirror ovarian transcription and act as estrus biomarkers. Therefore, the present study examined salivary transcript levels of estrus indicator proteins during the buffalo estrous cycle. In this study, we selected 04 transcripts viz., 17-beta-hydroxysteroid dehydrogenase type 1 (HSD17B1), inhibin Subunit Beta A (INHBA), heat shock 70 KDa Protein 1A (HSPA1A), and testin (TES) based on their function associated with estrous physiology as per the available literature [5] and our earlier findings [9, 14]. We used quantitative real-time polymerase chain reaction (qRT-PCR) to detect levels of selected transcripts in buffalo saliva and compared those levels within different stages of the estrous cycle. ROC was performed to detect transcripts' ability to discriminate estrus from other non-estrus stages. Finally, in silico analysis was performed to identify the involvement of transcripts in various signalling pathways.

\section{Materials And Methods}

\section{Selection of animals}

The study was conducted in buffaloes (Bubalusbubalis) maintained at Livestock Research Centre, ICARNational Dairy Research Institute, Karnal, Haryana. For the study, 10 heifers and 15 pluriparous buffaloes of $2^{\text {nd }}-5^{\text {th }}$ parity maintained under iso-managerial conditions were considered for the experimentation. The animals' nutrient requirement was mainly fulfilled with ad-libitum green fodder and measured amount of concentrate as per NRC requirement. The Murrah buffaloes were examined for the presence of dominant follicle (DF) or corpus luteum (CL) on the ovarian surface using per-rectal examination and trans-rectal ultrasonography (USG) (Aloka, MODEL UST-5820-5). Buffaloes with cyclic corpus luteum were administered with $\mathrm{PGF}_{2}$ a for estrus induction (Vetmate; $500 \mu \mathrm{g} \mathrm{I/M).} \mathrm{Samples} \mathrm{were} \mathrm{collected} \mathrm{from}$ the next spontaneous estrous cycle. The study was approved by the Institute Animal Ethics Committee (42-IAEC-18-9).

\section{Detection of estrus in buffaloes}

The onset of estrus in buffaloes was detected by physical observation of estrus signs, and confirmed by reproductive tract examination (uterine horn tonicity, cervical relaxation, tumefaction of vulva, hyperaemia or reddening of vulvar mucous membrane), biochemical parameters (cervicovaginal mucus crystallization, fluidity, spinnbarkeit value) and progesterone hormone estimation in blood serum. Buffalo bull parading was carried out twice a day, morning (6-7 AM), evening (5-6 PM) and each time at least for 30 minutes for the exhibition of estrus signs by female buffaloes. Estrus signs were observed: standing 
to be mounted, sniffing/licking the vulva, chin resting, flehmen's reaction, and mounting on or by other buffaloes, restlessness, bellowing, and frequent micturition. Further, trans-rectal ultrasonography was conducted to confirm the presence of preovulatory follicle (POF) on the day of estrus, the onset of ovulation after the end of estrus, and the presence of $C L$ during the diestrus stage. Samples were collected from buffaloes that have shown standing estrus along with other signs of estrus.

\section{Collection and processing of samples}

Saliva samples were collected in the morning before feeding, on the day of estrus ( $E$, day 0$)$, during proestrus \{early proestrus (EP, day -2$)$, late proestrus $(L P$, day -1$)$ \}, metestrus $(M E$, day +3$)$ and diestrus (day $D E+10)$ stage of the estrous cycle. Saliva $(\sim 5 \mathrm{~mL})$ was collected from healthy buffalo heifers $(n=8)$ and pluriparous buffaloes $(n=8)$ using a $20 \mathrm{ml}$ syringe without the needle in $15 \mathrm{~mL}$ centrifuge tubes in unstimulated condition by aspiration directly from the lower jaw of buffaloes. Samples were transported to the laboratory on ice and centrifuged at $3000 \mathrm{~g}$ for $10 \mathrm{~min}$ at $4^{\circ} \mathrm{C}$. Supernatant or cell-free saliva was transferred to another microcentrifuge tube and an equal amount of TRIzol reagent was added and further processed for RNA isolation and gene expression study.

\section{Collection and analysis of cervico-vaginal mucus parameters}

The cervico-vaginal mucus (CVM) was collected from buffaloes during the peri-estrus period (proestrus, estrus, and metestrus) by aspiration method using a sterile blue sheath (IMV Technologies, France) fitted with a universal Al gun through the recto-vaginal method. Immediately after collection, samples were transported to the laboratory on ice. Initial parameters of CVM such as quantity, consistency, and crystallization/ fern pattern were recorded. For crystallization/ fern pattern, a small quantity of mucus was smeared onto a glass slide and the smear was allowed to dry at room temperature. Then the slide was observed under the microscope (Nikon Eclipse Ti, Japan) to confirm the estrus stage.

\section{Blood collection and its processing for estimation of progesterone hormone}

Blood samples were collected during different estrous cycle stages using $9 \mathrm{~mL}$ serum collection tubes (BD Vacutainer). Blood samples were kept at room temperature for $1 \mathrm{hr}$ in slanting position and centrifuged at $3000 \mathrm{rpm}$ for $10 \mathrm{~min}$. Serum was separated and stored in cryovials at $-80^{\circ} \mathrm{C}$ for further progesterone estimation using an ELISA kit (Cayman Chemical, USA) according to the manufacturer's protocol. The progesterone concentration was measured in Nano Quant Infinite M200 PRO (TECAN, Seestrasse 103, and Switzerland) at a wavelength of $410 \mathrm{~nm}$.

\section{Total RNA extraction}

Total RNA was extracted using TRIzol reagent (Sigma Aldrich, St. Louis, USA) as per the manufacturer's instructions with slight modifications. In brief, TRIzol reagent was added to each microcentrifuge tube containing saliva and vortexed for $15 \mathrm{sec}$, followed by the addition of chloroform ( $200 \mu \mathrm{L})$ and vortexed for $15 \mathrm{sec}$ for mixing of contents properly. Samples were kept on ice for $10 \mathrm{~min}$ and centrifuged at $11363 \mathrm{~g}$ for $10 \mathrm{~min}$ at $4 \mathbb{} \mathrm{C}$; the uppermost aqueous phase (containing RNA) was collected in a new $2 \mathrm{~mL}$ 
microcentrifuge tube without disturbing the interface. An equal quantity of isopropanol was added to each tube and kept at -80冈C overnight. The total content of the tube was loaded to the respective RNeasy mini spin columns (RNeasy mini kit, Qiagen) placed in a $1.5 \mathrm{~mL}$ collection tube, and the lid was closed properly and centrifuged for $1.5 \mathrm{~min}$ at $11363 \mathrm{~g}$. The flow-through was discarded and $600 \mu \mathrm{L}$ of chilled ethanol (75\%) was added to each column and centrifuged for $1.5 \mathrm{~min}$ at $11363 \mathrm{~g}$ twice. The flow-through was discarded. The column was centrifuged again at $11363 \mathrm{~g}$ for $2 \mathrm{~min}$ to remove the traces of ethanol. The RNeasy Mini spin column was placed in a new $1.5 \mathrm{~mL}$ collection tube and elution of RNA was done by placing $20 \mu \mathrm{L}$ of RNase free water on the spin column membrane and kept for 5 minutes on ice followed by centrifugation for $2.0 \mathrm{~min}$ at $11363 \mathrm{~g}$. The step was repeated twice to get the maximum yield of RNA. Concentration and purity (260/280) of total RNA extracted was measured in Nano Quant Infinite M200 PRO (TECAN, Seestrasse 103, and Switzerland). The samples with a 260/280 ratio between 1.8-2.0 were used for cDNA synthesis and downstream processing.

\section{cDNA synthesis and optimization of PCR}

Total RNA (250 ng) was reverse transcribed into cDNA in a $20 \mu \mathrm{L}$ reaction mixture using RevertAid Firststrand cDNA synthesis kit (Thermo Scientific, USA) as per the manufacturer's protocol. Reverse transcription reaction was carried out at $65^{\circ} \mathrm{C}$ for $5 \mathrm{~min}, 42^{\circ} \mathrm{C}$ for $60 \mathrm{~min}$, and $70^{\circ} \mathrm{C}$ for $5 \mathrm{~min}$ in a thermal cycler (Bio-Rad, USA). In brief, $12 \mu \mathrm{L}$ of reaction mixture containing $250 \mathrm{ng}$ of the total RNA, $0.5 \mu \mathrm{L}$ of oligo-dT primer, $0.5 \mu \mathrm{L}$ of random primer, nuclease-free water to adjust the volume, was incubated at 65 ${ }^{\circ} \mathrm{C}$ for $5 \mathrm{~min}$. On completion of incubation following components \{5X Reaction Buffer, $4 \mu \mathrm{L}$; Ribolock RNase Inhibitor, $1 \mu \mathrm{L}(20 \mathrm{U} / \mu \mathrm{l}) ; 10$ mM dNTP Mix, $2 \mu \mathrm{L}$; RevertAid M-MuLV RT, $1 \mu \mathrm{L}(200 \mathrm{U} / \mu \mathrm{l})\}$, nucleasefree water to make the volume up to $20 \mu \mathrm{L}$ ) were added to the above reaction mixture and contents were appropriately mixed, incubated at $42^{\circ} \mathrm{C}$ for $60 \mathrm{~min}$ in a thermal cycler. The reaction was finally terminated by heating at $70^{\circ} \mathrm{C}$ for $5 \mathrm{~min}$. The reverse transcription reaction product (CDNA) was stored at $-20^{\circ} \mathrm{C}$ until further use. The sequences of the selected genes were retrieved from the NCBI database and primers were designed using Gene tool software (Table 1). Cyclic conditions of PCR were optimized for each target gene and a reaction mixture of $10 \mu \mathrm{L}$ was prepared containing $1 \mu \mathrm{L}$ of cDNA, 5.0 $\mu \mathrm{L}$ Dream Taq PCR Master Mix (Thermo Scientific, USA), and $0.5 \mu \mathrm{M}$ of each forward and reverse primer and nuclease-free water to adjust the volume and PCR reaction was set for initial denaturation at $95^{\circ} \mathrm{C}$ for $3 \mathrm{~min}$ followed by 35 cycles at $95^{\circ} \mathrm{C}$ for $30 \mathrm{sec}$, annealing temperature for the gene for 30 seconds, $72{ }^{\circ} \mathrm{C}$ for $30 \mathrm{sec}$ and final extension at $72^{\circ} \mathrm{C}$ for $1.2 \mathrm{~min}$ in a Gradient Thermal Cycler (C1000 Touch Thermal Cycle, Biorad). After optimization, the presence of a single amplicon was confirmed by agarose gel (1.5\%) electrophoresis. 
Table 1

Details of primers used in the study

\begin{tabular}{|c|c|c|c|c|}
\hline Gene Name & Primer sequence & $\mathrm{Ta}\left({ }^{\circ} \mathrm{C}\right)$ & $\begin{array}{l}\text { Amplicon } \\
\text { Size (bp) }\end{array}$ & Accession number \\
\hline HSPA1A-FP & GGTGCAGGAGGCGGAAAAGTA & 65 & 112 & XM_006041893.2 \\
\hline HSPA1A-RP & АTCCTCCACGGCGCTCTTCAT & & & \\
\hline TES-FP & CACCAAGTACACCACCCTGA & 60 & 138 & XM_025291152.1 \\
\hline TES-RP & GGAGCCCATTCGTAGGTAAC & & & \\
\hline HSD17B1-FP & AAGTCAGCGTTCCACGACAA & 60 & 112 & XM_006055742.2 \\
\hline HSD17B1-RP & TTTATTGCGGGGCGAGAGAA & & & \\
\hline INHBA-FP & GATGGTGGAGGCCGTCAAGAA & 65 & 170 & XM_006080472.2 \\
\hline INHBA-RP & TCCGTCCGATGTCGTCCTCTA & & & \\
\hline GAPDH-FP & GGTCATCATCTCTGCGCCTT & 60 & 185 & XM_006065800.2 \\
\hline GAPDH-RP & CGTGGACGGTGGTCATAAGT & & & \\
\hline
\end{tabular}

\section{Real-Time PCR}

Salivary levels of mRNAs were determined by qRT-PCR in a CFX96 Touch Real-Time PCR Detection System (Biorad, USA) using PowerUp ${ }^{\mathrm{TM}}$ SYBR $^{\mathrm{TM}}$ Green Master Mix. In brief, $10 \mu \mathrm{L}$ PCR reaction mixture containing $1 \mu \mathrm{L}$ of $\mathrm{cDNA}, 0.5 \mu \mathrm{M}$ of each of forward and reverse primer, $5.0 \mu \mathrm{L}$ of PowerUp ${ }^{\mathrm{TM}} \mathrm{SYBR}^{\mathrm{TM}}$ Green master mix, and rest of the volume were adjusted with nuclease-free water. All the samples were run in duplicate along with non-template control. The real-time PCR was performed under thermocycling conditions: $95^{\circ} \mathrm{C}$ for $10 \mathrm{~min}, 40$ cycles of $95^{\circ} \mathrm{C}$ for $30 \mathrm{sec}$, annealing temperature (Table 1) for $10 \mathrm{sec}$, and final extension at $72{ }^{\circ} \mathrm{C}$ for $15 \mathrm{~min}$. The Amplification plot and melting curves for all the reactions were analyzed for the specific amplification in all samples. Expression of GAPDH was taken as endogenous control. The relative quantification of the target gene was done using the $2^{-\Delta \Delta C T}$ method [14] (Livak and Schmittgen, 2001). The expression of genes in different samples was estimated as:

Relative gene expression, i.e., Fold change $=2^{-\Delta \Delta C t}$

$\Delta \Delta \mathrm{Ct}=\Delta \mathrm{Ct}$ of samples (EP, LP, E, ME)- $\Delta \mathrm{CT}$ of $\mathrm{DE}$ samples

Where $\triangle \mathrm{Ct}=\mathrm{Ct}$ of target gene $\mathrm{C} \mathrm{Ct}$ of reference gene $(G A P D H)$

\section{Bioinformatics analysis and statistical analysis}

Search Tool for the Retrieval of Interacting Genes (STRING) (https://www.string-db.org/), an online tool, was used to understand the involvement of selected genes in different signalling pathways. Statistical 
analysis was performed by one-way analysis of variance (ANOVA) and post hoc Tukey test or paired t-test for group-wise comparison using SPSS software (version 16). Results are represented as mean \pm SEM. Receiver operating characteristic (ROC) curve analysis was performed using $\triangle C$ t values of the HSD17B1 and HSPATA in the EP, LP, E, ME, and DE stage samples.

\section{Results}

\section{Identification and confirmation of estrus}

Estrus was determined by physical signs of estrus, confirmed by reproductive tract examination (uterine horn tonicity, tumefaction of vulva, hyperaemia of vulval mucous membrane, cervical relaxation), biochemical parameters (CVM characteristics), and progesterone hormone in blood serum. Behavioural signs of estrus are shown in Table 2. Among behavioural signs, standing to be mounted, flehmen's reaction, and licking/ sniffing the vulva by teaser bull were mostly observed in female buffaloes during estrus. Other estrus signs were categorised as mild, moderate and intense based on their intensity of expression in individual animals, as shown in Table 3. Tonicity of the uterus was found to be mostly intense (89.5\%) during estrus and in a few buffaloes, moderate tonocity $(10.5 \%)$ was also recorded. Similarly, CVM discharge and hyperaemia/ reddening of the vulval mucous membrane were mostly intense during estrus and in only $10.5 \%$ buffaloes, it was moderate. CVM crystallization/ fern pattern was found to be typical with score 3 and 4 in $79.3 \%$ and atypical with score 2 in $21.1 \%$ buffaloes (Fig. S1).

Transrectal-USG revealed the presence of dominant follicle (DF) during the follicular phase, and the size of DF was $11.5 \mathrm{~mm}, 12.5 \mathrm{~mm}$, and $13.3 \mathrm{~mm}$ during EP, LP, and E, respectively (Fig. 1). The absence of preovulatory follicle confirmed ovulation during the $M E$ and $C L$ presence during the $D E$. Serum progesterone levels was estimated and it was found lowest at $E(0.32 \pm 0.06 \mathrm{ng} / \mathrm{mL}, P<0.05), L P(0.51 \pm$ $0.12 \mathrm{ng} / \mathrm{mL}, \mathrm{P}<0.05), \mathrm{EP}(0.93 \pm 0.03 \mathrm{ng} / \mathrm{mL}, \mathrm{P}<0.05)$ as compared to $\mathrm{ME}(1.58 \pm 0.24 \mathrm{ng} / \mathrm{mL})$ and $\mathrm{DE}$ $(2.84 \pm 0.26 \mathrm{ng} / \mathrm{mL})$ stages (Table 4).

Table 2

Expression of estrus signs in buffaloes

\begin{tabular}{|ll|}
\hline Behaviour Signs of estrus & \% of animals showing estrus signs \\
\hline Standing to be mounted & 78.57 \\
\hline Licking/ Sniffing of vulva & 85.7 \\
\hline Flehmen's Response & 78.57 \\
\hline Chin Resting & 57.14 \\
\hline Frequent micturition & 64.29 \\
\hline
\end{tabular}


Table 3

Intensity of expression of other estrus signs in buffaloes

\begin{tabular}{|llll|}
\hline Behaviour Signs of Estrus & \multicolumn{3}{l|}{ Intensity of expression (\%) } \\
\hline & Mild & Moderate & Intense \\
\hline Uterine horn tonicity & - & 10.5 & 89.5 \\
\hline Vulva tumefaction & 5.3 & 13.7 & 80.2 \\
\hline Hyperaemia/ reddening of vulval mucous membrane & - & 10.5 & 89.5 \\
\hline Cervico-vaginal mucus discharge & - & 10.5 & 89.5 \\
\hline
\end{tabular}

Table 4

Serum progesterone concentration $(\mathrm{ng} / \mathrm{mL})$ during different stages of estrous cycle in buffaloes

\begin{tabular}{|ll|}
\hline Stage of estrous cycle & Progesterone concentration $(\mathrm{ng} / \mathrm{mL})$ \\
\hline Early proestrus (Day-2) & $0.93 \pm 0.03^{\mathrm{a}}$ \\
\hline Late Proestrus (day- 1$)$ & $0.51 \pm 0.12^{\mathrm{ab}}$ \\
\hline Estrus (day 0) & $0.32 \pm 0.06^{\mathrm{b}}$ \\
\hline Metestrus (day +3$)$ & $1.58 \pm 0.24^{\mathrm{c}}$ \\
\hline Diestrus (day +10$)$ & $2.84 \pm 0.26^{\mathrm{d}}$ \\
\hline The mean bearing different superscripts $(\mathrm{a}, \mathrm{b}, \mathrm{c}, \mathrm{d})$ varied significantly $(\mathrm{p}<0.05)$ \\
\hline
\end{tabular}

\section{Target Mrna Levels In Cell-free Saliva}

We selected 04 candidate genes based on our earlier findings and available literature (Table 1) for qRTPCR analysis. Salivary levels of $H S D 17 B 1$ and $H S P A 1 A$ were significantly altered during different stages of the estrous cycle in both cyclic heifers and pluriparous buffaloes (Figs. 2 and 3). HSD17B1 level was significantly $(P<0.01)$ increased at the $E$ stage as compared to other stages in both cyclic heifers $(E P / D E$ 2.43-fold; LP/DE 3.06-fold; E/DE 11.9-fold; ME/DE 1.0-fold) and pluriparous buffaloes (EP/DE 1.46-fold; LP/DE 2.49-fold; E/DE 7.21-fold; ME/DE 1.21-fold) (Fig. 2A and 3A). HSPA1A level in heifers was found to be significantly $(P<0.01)$ higher at $E(15.18$ - fold) followed by LP $(3.23$-fold $)$, EP $(0.93$-fold), and ME (0.86-fold) as compared to the DE stage (Fig. 2B). A similar trend was also observed in pluriparous buffaloes wherein the highest level $(P<0.05)$ of HSPA1A was recorded at $E(E / D E$ 4.61-fold; EP/DE 1.33fold; LP/DE 2.54-fold; ME/DE 1.15-fold) compared to other stages (Fig. 3B). In contrast, mRNA levels of $I N H B A$ in the saliva of cyclic heifers did not vary significantly at $E$ (E/DE 2.47-fold; EP/DE 1.7-fold; LP/DE 2.9-fold; ME/DE 1.2-fold, $\mathrm{P}=0.117$ ) (Fig. 2C). However, in pluriparous buffaloes, INHBA levels increased at E (4.94-fold) as compared to ME (0.9-fold) but not from EP (2.79-fold) and LP (4.28-fold) stages (Fig. 3C). 
The salivary level of the TES gene revealed its higher level at $E(3.65$-fold, $P<0.05)$ as compared to EP (1.13-fold) and DE stage but not from LP (2.52-fold) and ME (1.44-fold) stage of cyclic buffalo heifers (Fig. 2D). Similarly, its level did not significantly change at E (2.8-fold) as compared to EP (1.7-fold), LP (2.57-fold) and ME stage (1.3-fold) of pluriparous buffaloes (Fig. 3D).

\section{Receiver Operating Characteristics (Roc) Curve Analysis To Predict The Diagnostic Ability Of Salivary Transcripts}

ROC curve analysis was performed to determine the discriminatory ability of HSPA1A and HSD17B1 for differentiating $E$ from other stages of the estrous cycle. ROC curve analysis showed that at the 0.26 cutoff value, the sensitivity and specificity of HSPA1A in differentiating the $E$ stage from EP, LP, ME, and DE stages were $100 \%$ and $95.65 \%$, respectively; the AUC was 0.99 at a $95 \%$ confidence interval $(P<0.0001)$ as shown in Fig. 4. Similarly, the cut-off value for HSD17B1 was 0.095 and the sensitivity and specificity in differentiating the $E$ from EP, LP, ME, and DE stages were $90 \%$ and $94.74 \%$, respectively; the AUC was 0.96 at $95 \%$ confidence interval $(P<0.0001)$ (Fig. 5).

\section{In silico analysis for identification of signalling pathways}

In silico analysis was performed for HSD17B1 and HSPA1A genes to identify their involvement in different signalling pathways using the online STRING tool. It revealed a significant association of $H S D 17 B 1$ with other genes such as CYP19A1, CYP1A1, CYP2A13, CYP1B1, HSD17B2, HSD17B3, HSD17B7, HSD17B and involved in steroid hormone biosynthesis/ ovarian steroidogenesis and aromatase signalling pathways $(\mathrm{P}=8.10 \mathrm{E}-15)$, Fig. S2. Similarly, HSPA1A in association with other genes (BAG1-3, BAG5, DNAJA1-2, $D N A J B 1, D N A J B 1, D N A J C 1)$, regulates the cellular response to the stress pathway $(\mathrm{P}=7.42 \mathrm{e}-06)$, Fig. $\mathrm{S} 3$.

\section{Discussion}

Accurate and efficient estrus detection is important for successful conception and efficient reproduction management in farm animals. Because buffalo don't show obvious estrus signs, identifying estrus biomarkers for this species is of paramount importance. The present study examined the potential of the HSD17B1, HSPA1A, INHBA, and TES genes for the detection of estrus in the saliva of buffalo heifers and pluriparopus buffaloes. In recent years, several studies performed on saliva reported biomarker potential of circulating cell-free RNAs including mRNA and miRNA for diagnosis of several diseases $[4,8,15]$ and physiological alterations $[9,10]$. Among the 4 transcripts evaluated in the present study, we found elevated levels of $H S D 17 B 1$ and $H S P A 1 A$ during estrus compared to other estrous cycle stages in both cyclic heifers and pluriparous buffaloes. The highest level of HSD17B1 in saliva coincided with the presence of a large dominant follicle and its level decreased after ovulation and during the luteal phase, suggesting its crucial role in granulosa cells function, ovarian steroidogenesis, and functional status of the dominant follicle. Shashikumar et al. [13] also identified HSD17B1 protein in the saliva of buffaloes, especially during the estrus stage and not at any other stages of the estrous cycle. HSD17B1 is a short- 
chain alcohol dehydrogenase reductase family member that catalyzes the conversion of low active 17ketosteroids to the highly active $17 \beta$ hydroxysteroids and vice versa [16]. Although several $H S D 17 B$ enzymes play a role in steroid metabolism, the HSD17B1 enzyme preferably catalyzes the estrone to estradiol [17] and plays a central role in granulosa cell estradiol synthesis and ovarian function [16]. Other studies demonstrated down-regulation of this enzyme in luteinizing granulosa cells and not present in corpus luteum, further supporting our findings on the lower level of HSD17B1 during the metestrus and diestrus stage $[18,19]$. Similarly, the transcriptome profile of granulosa cells from bovine ovarian follicles showed down regulation of $H S D 17 B 1$ gene in small atretic follicles than healthy follicles [20] demonstrating its important role in follicular development. All these studies demonstrated cyclic variation in the expression of $H S D 17 B 1$ in granulosa cells. Since $H S D 17 B 1$ is one of the major enzymes regulating ovarian estradiol production, there is a possibility of excretion of this enzyme into circulation and then into the saliva. Another possibility is that higher estradiol levels during late proestrus and estrus may induce the expression of $H S D 17 B 1$ in salivary glands, leading to its increased level in saliva, which needs to be explored.

Interestingly, we observed elevated levels of HSPA1A towards late proestrus and a very high level during estrus than other stages of the estrous cycle. Muthukumar et al. [5] also identified HSP7O protein in the CVM and saliva of buffaloes, particularly during the estrus stage and not at the diestrus stage of the estrous cycle. An earlier study by Onteru et al. [9] using direct saliva transcript analysis also demonstrated a higher level of $H S P 70$ transcript in saliva during estrus than diestrus stage, suggesting it as a good indicator of estrus in buffaloes. Previously, we also identified $H S P 70$ protein in the saliva of buffaloes during the estrus stage and not at any other stages, suggesting stage-specific regulation of HSPATA during the estrous cycle [13]. HSPA1A is a molecular chaperone and it protects cells from stress by promoting the folding of nascent polypeptides and correcting the misfolding of denatured proteins [21]. A previous study also reported its involvement in the estrogen signalling pathway. HSP7O regulates the responsiveness of ERa to its ligands (17ß-estradiol) and their binding to estrogen-response elements (ERE) and induces transcription of target genes [22]. Estradiol hormone induces the estrus signs in animals and estradiol level increased to a higher level just before the onset of estrus $(22.4-35 \mathrm{pg} / \mathrm{mL})$ $[23,24]$ and higher expression of HSPA1A during estrus may be a protective mechanism to protect cells from estradiol-induced stress. Previously it was reported that estradiol treatment-induced heat shock proteins expressions in rat brain vasculature $[25,26]$ demonstrate HSPs induction as an important protective mechanism for estrogen induced stress or injury. Suggestive increased expression of HSPA1A level during estrus could be a protection from estrogen-induced stress to granulosa cells and its possible role in follicular growth and steroidogenesis process. Hatzirodos et al. [20] also reported down-regulation of HSPA1A expression in small atretic follicles than healthy follicles, demonstrating its essential role in follicular development.

In addition, we also observed high levels of INHBA during estrus than the ME and DE stages but not from EP and LP stages. In contrast, Shashikumar et al. [13] reported INHBA protein in buffalo saliva during estrus and not at any other stages. In concordance with our observation, an increased level of plasma inhibin A concentration was reported during the follicular phase i.e., from $\sim 50 \mathrm{pg} / \mathrm{mL}$ before luteolysis to 
a peak level of $\sim 125 \mathrm{pg} / \mathrm{mL}$ during preovulatory estradiol/LH surge and then decreased sharply to a concentration of $55 \mathrm{pg} / \mathrm{mL}$ after commencement of ovulation [27]. Inhibin belongs to the transforming growth factor (TGF $\beta$ ) superfamily. Several tissues and reproductive organs such as ovarian granulosa cells, fetus, placenta, express INHBA. It is mainly synthesized and secreted by the follicular granulosa cells and regulates proliferation, apoptosis of granulosa cells, steroidogenesis, and follicular development during the estrous cycle [28]. It also plays a vital role in maintaining a species-specific number of ovulations. Hatzirodos et al. [20] also reported down-regulation of INHBA expression in small atretic follicles than healthy follicles, demonstrating its important role in follicular development. Our findings are the first report on salivary INHBA transcript level in general and with the buffalo estrous cycle. A higher level of INHBA during proestrus and estrus can be correlated with its involvement in the selection and development of the dominant follicle.

Further, we also observed an increased level of TES gene on the estrus day compared to DE stage but not from EP, LP and ME stages. In contrast, Shashikumar et al. [13] reported TES protein in buffaloes' saliva exclusively during the estrus stage and not at any other estrous cycle stages. Immuno-histochemical study in the rat has identified localization of TES protein in the granulosa cells and its expression increased during follicular development but is down-regulated drastically when the follicle is undergoing atresia [29]. Testin is a $47 \mathrm{kDa}$ protein and composed of 421 amino acids, and it has 3-C terminal LIM domain. It interacts with the Vangl2 gene during female reproductive tract development in mice [30]. Suggestive increased expression of the TES gene in saliva during the estrus stage can be correlated with its involvement in folliculogenesis and follicular development.

To further understand the functions of $H S P A 1 A$ and $H S D 17 B 1$, we performed in silico analysis to predict possible roles in different signalling pathways using the STRING online tool (v.11.5). HSD17B1 plays an important role in ovarian function, involving steroid hormone biosynthesis/ ovarian steroidogenesis and aromatase signalling pathways. Similarly, HSPA1A regulates the cellular response to the stress pathway and may be a protective mechanism to protect granulosa cells from estradiol-induced stress during estrus. In addition, ROC curve analysis also strongly indicated the ability of HSPA1A and HSD17B1 to differentiate estrus from other stages of the estrous cycle. Finally, the dynamic presence of the above two transcripts in saliva during the estrous cycle indicates their biomarker potential for estrus detection in buffaloes. However, this data needs to be validated in a large cohort of buffaloes, including different breeds and seasons, to further qualify them as estrus biomarkers.

\section{Conclusion}

Using cell-free salivary transcript analysis, we identified significantly higher levels of $H S D 17 B 1$ and HSPA1A transcripts in buffalo saliva during the estrus stage and their potential as biomarkers for distinguishing estrus from other non-estrus stages in both cyclic heifers and pluriparous buffaloes. These findings may be helpful to develop a salivary transcript-based-estrus detection tool in the near future.

\section{Declarations}




\section{Author contributions}

RKB, TKM, AK: Conceptualized the study and arrange the funds. SS and SD: carried out the sampling. MP: performed the designing of the primers. SS, LJ: Performed the mRNA expression analysis. RKB and MP: performed the statistical analysis. SS and RKB: wrote the paper and all other authors reviewed the paper.

\section{Data availability}

The authors confirm that the data supporting the findings of this study are available within the article.

\section{Conflict of interest}

The authors declared no conflict of interest.

\section{Ethical approval}

The animal study was approved by IAEC, NDRI, Karnal [42-IAEC-18-9].

\section{Acknowledgements}

The authors are thankful to the Director, ICAR-National Dairy Research Institute for providing all facilities to carry out the research work.

\section{Funding}

This work was supported by the Department of Biotechnology, Govt. of India [Grant No.BT/PR23365/AAQ/1/688/2017].

\section{References}

[1] Kumar P, Shankar Rao TK, Kumar N, Chaurasia S, Patel NB (2013) Heat detection techniques in cattle and buffalo. Vet World 6:363-369.

[2] Suthar VS, Dhami AJ (2010) Estrus Detection Methods in Buffalo. Vet World 3.

[3] Selvam RM, Archunan G (2017) A combinatorial model for effective estrus detection in Murrah buffalo. Vet World 10:209.

[4] Li Y, John MAS, Zhou X, Kim Y, Sinha U, Jordan RC, Eisele D, Abemayor E, Elashoff D, Park NH, Wong DT (2004) Salivary transcriptome diagnostics for oral cancer detection. Clin Cancer Res 10:8442-8450.

[5] Muthukumar S, Rajkumar R, Rajesh D, Saibaba G, Liao CC, Archunan G, Padmanabhan P, Gulyas B (2014) Exploration of salivary proteins in buffalo: an approach to find marker proteins for estrus. FASEB J 28:4700-4709. 
[6] Yang J, Wei F, Schafer C, Wong DT (2014) Detection of tumor cell-specific mRNA and protein in exosome-like microvesicles from blood and saliva. PLoS One. 9, e110641.

[7] Oh SY, Kang SM, Kang SH, Lee HJ, Kwon TG, Kim JW, Lee ST, Choi SY, Hong SH, (2020) Potential salivary mRNA biomarkers for early detection of oral cancer. J Clin Med 9:243.

[8] Zhang L, Farrell JJ, Zhou H, Elashoff D, Akin D, Park NH, Chia D, Wong DT (2010a) Salivary transcriptomic biomarkers for detection of resectable pancreatic cancer. Gastroenterology 138:949-957.

[9] Onteru SK, Baddela VS, Ravinder R, Kaipa O, Nayan V, Singh P, Baithalu RK, Singh D (2016) Direct saliva transcript analysis as a novel non-invasive method for oestrus marker detection in buffaloes. Biomarkers 21:99-101.

[10] Singh P, Golla N, Singh P, Baddela VS, Chand S, Baithalu RK, Singh D, Onteru S (2017) Salivary miR16, miR-191 and miR-223: intuitive indicators of dominant ovarian follicles in buffaloes. Mol Genet Genom 292:935-953.

[11] Hebbar A, Chandel R, Rani P, Onteru SK, Singh D (2021) Urinary cell-free miR-99a-5p as a potential biomarker for estrus detection in buffalo. Front Vet Sci 8.

[12] An X, Zhang Y, Li F, Wang Z, Yang S, Cao B (2021) Whole Transcriptome Analysis: Implication to Estrous Cycle Regulation. Biology 10:464.

[13] Shashikumar NG, Baithalu RK, Bathla S, Ali SA, Rawat P, Kumaresan A, Kumar S, Maharana BR, Singh, G, Kumar DP, Singh SK (2018) Global proteomic analysis of water buffalo (Bubalus bubalis) saliva at different stages of estrous cycle using high throughput mass spectrometry. Theriogenology 110:52-60.

[14] Livak KJ, Schmittgen TD (2001) Analysis of relative gene expression data using real-time quantitative PCR and the 2- $\triangle \Delta C T$ method. Methods 25:402-408.

[15] Zhang L, Xiao H, Karlan S, Zhou H, Gross J, Elashoff D, Akin D, Yan X, Chia D, Karlan B, Wong DT (2010b) Discovery and preclinical validation of salivary transcriptomic and proteomic biomarkers for the non-invasive detection of breast cancer. PloS One. 5, e15573.

[16] Hakkarainen J, Jokela H, Pakarinen P, Heikela H, Kätkänaho L, Vandenput L, Ohlsson C, Zhang FP, Poutanen M (2015) Hydroxysteroid (17 $\beta$ ) dehydrogenase 1-deficient-female mice present with normal puberty onset but are severely subfertile due to a defect in luteinization and progesterone production. FASEB J. 29:3806-3816.

[17] Nokelainen P, Puranen T, Peltoketo H, Orava M, Vihko P, Vihko R (1996) Molecular cloning of mouse $17 \beta$-Hydroxysteroid Dehydrogenase Type 1 and characterization of enzyme activity. Eur J Biochem 236:482-490. 
[18] Ghersevich S, Nokelainen P, Poutanen M, Orava M, Autio-Harmainen H, Rajaniemi H, Vihko R (1994) Rat 17 beta-hydroxysteroid dehydrogenase type 1: primary structure and regulation of enzyme expression in rat ovary by diethylstilbestrol and gonadotropins in vivo. Endocrinology 135:1477-1487.

[19] Pelletier G, Li S, Ren L, Labrie F (2004) Localization of 17ß-hydroxysteroid dehydrogenase type 1 mRNA in mouse tissues. J Mol Endocrinol 33:459-465.

[20] Hatzirodos N., Irving-Rodgers HF, Hummitzsch K, Harland ML, Morris SE, Rodgers RJ (2014) Transcriptome profiling of granulosa cells of bovine ovarian follicles during growth from small to large antral sizes. BMC Genom 15:1-19.

[21] Lindquist S, Craig EA (1988) The heat-shock proteins. Annu Rev Genet 22:631-677.

[22] Pratt WB, Toft DO (1997) Steroid receptor interactions with heat shock protein and immunophilin chaperones. Endocr Rev 18:306-360.

[23] Roy KS, Prakash BS (2009) Plasma progesterone, oestradiol-17 $\beta$ and total oestrogen profiles in relation to oestrous behaviour during induced ovulation in Murrah buffalo heifers. J Anim Physiol Anim Nutr 93:486-495.

[24] Mondal S, Suresh KP, Nandi S (2010) Endocrine profiles of oestrous cycle in buffalo: a meta-analysis. Asian-australian J Anim Sci 23:169-174.

[25] Lu A, Ran RQ, Clark J, Reilly M, Nee A, Sharp FR (2002) 17- $\beta$-Estradiol induces heat shock proteins in brain arteries and potentiates ischemic heat shock protein induction in glia and neurons. J Cereb Blood Flow Metab 22:183-195.

[26] Raval AP, Borges-Garcia R, Javier Moreno W, Perez-Pinzon MA, Bramlett H (2013) Periodic 17 $\beta$ estradiol pretreatment protects rat brain from cerebral ischemic damage via estrogen receptor- $\beta$. PloS one. 8:607-616.

[27] Bleach EC, Glencross RG, Feist SA, Groome NP, Knight PG (2001) Plasma inhibin A in heifers: relationship with follicle dynamics, gonadotropins, and steroids during the estrous cycle and after treatment with bovine follicular fluid. Biol Reprod 64:743-752.

[28] Stangaferro ML, Matiller V, Díaz PU, Ortega HH, Rey F, Rodríguez FM, Silva MA, Salvetti NR (2014) Role of activin, inhibin, and follistatin in the pathogenesis of bovine cystic ovarian disease. Anim Reprod Sci 148:97-108.

[29] Zhu LJ, Moo-Young AM, Wayne Bardin C, Yan Cheng C (1997) Immunohistochemical localization of testin in the female reproductive system of the rat is consistent with its involvement in the turnover of specialized junctional complexes. Biol Reprod 56:1330-1335. 
[30] Ren D, Kelly M, Kim SM, Grimsley C, Wang J, Chen P (2013) Testin interacts with vangl2 genetically to regulate inner ear sensory cell orientation and the normal development of the female reproductive tract in mice. Dev Dyn 242:1454-1465.

\section{Figures}
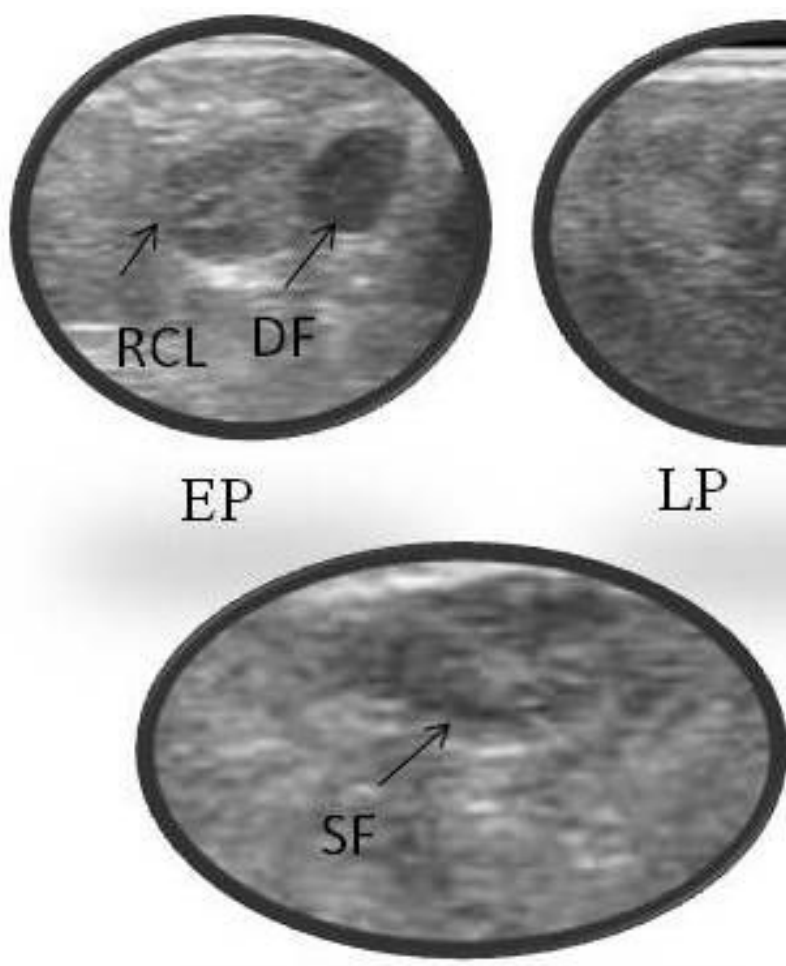

ME

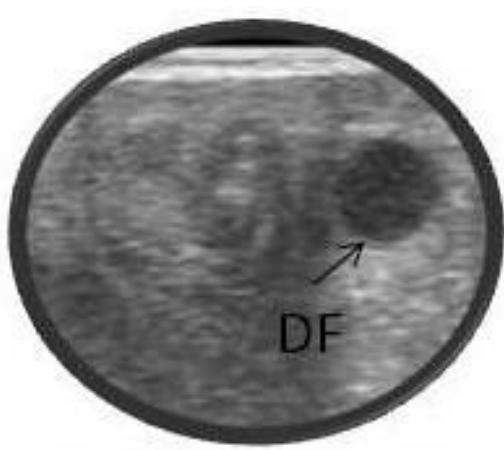

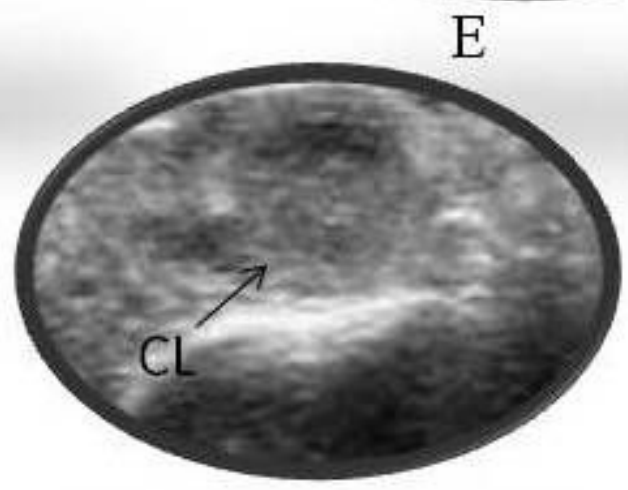

$\mathrm{DE}$

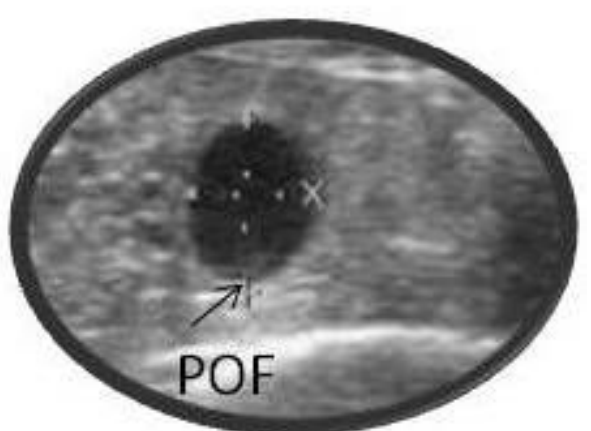

E

\section{Figure 1}

Ultrasonography of ovary during different stages of estrous cycle in buffaloes (EP, Early Proestrus (day -2); LP, Late Proestrus (day -1); E, Estrus (day 0); ME Metestrus (day+3); Diestrus (day +10); DF, Dominant Follicle; SF, Small Follicle; MF, Medium Follicle; POF, Preovulatory Follicle; RCL, Regressing Corpus Luteum; CL, Corpus Luteum) 

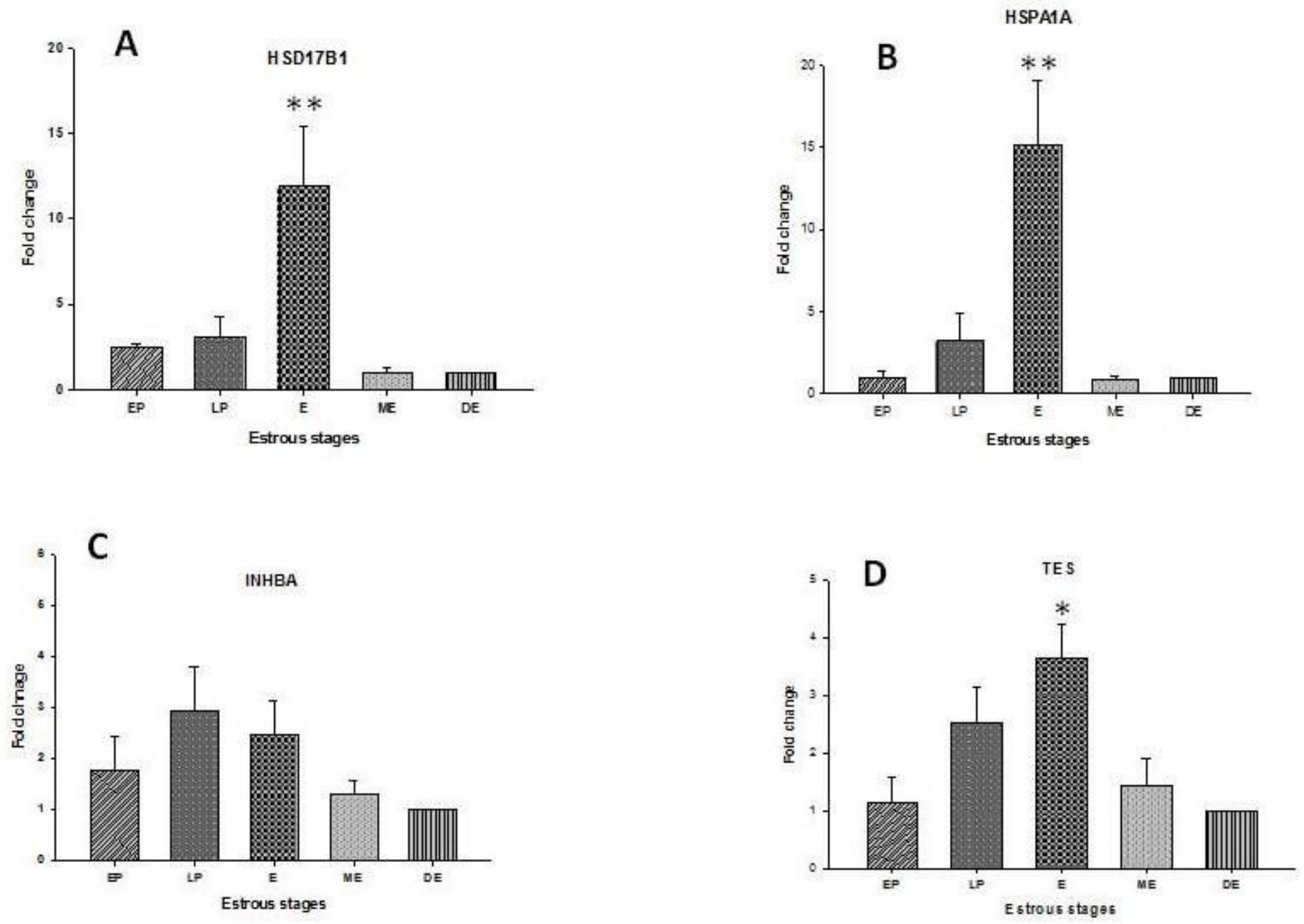

Figure 2

Quantitative real-time PCR analysis of (A) HSD17B1, (B) HSPA1A, (C) INHBA and (D) TES transcripts in saliva of cyclic buffalo heifers during early proestrus (EP), late proestrus (LP), estrus (E), metestrus (ME) and diestrus (DE) stages. Each bar represents the mean \pm SE of gene expression data $* P<0.05, * * P<0.01$ 

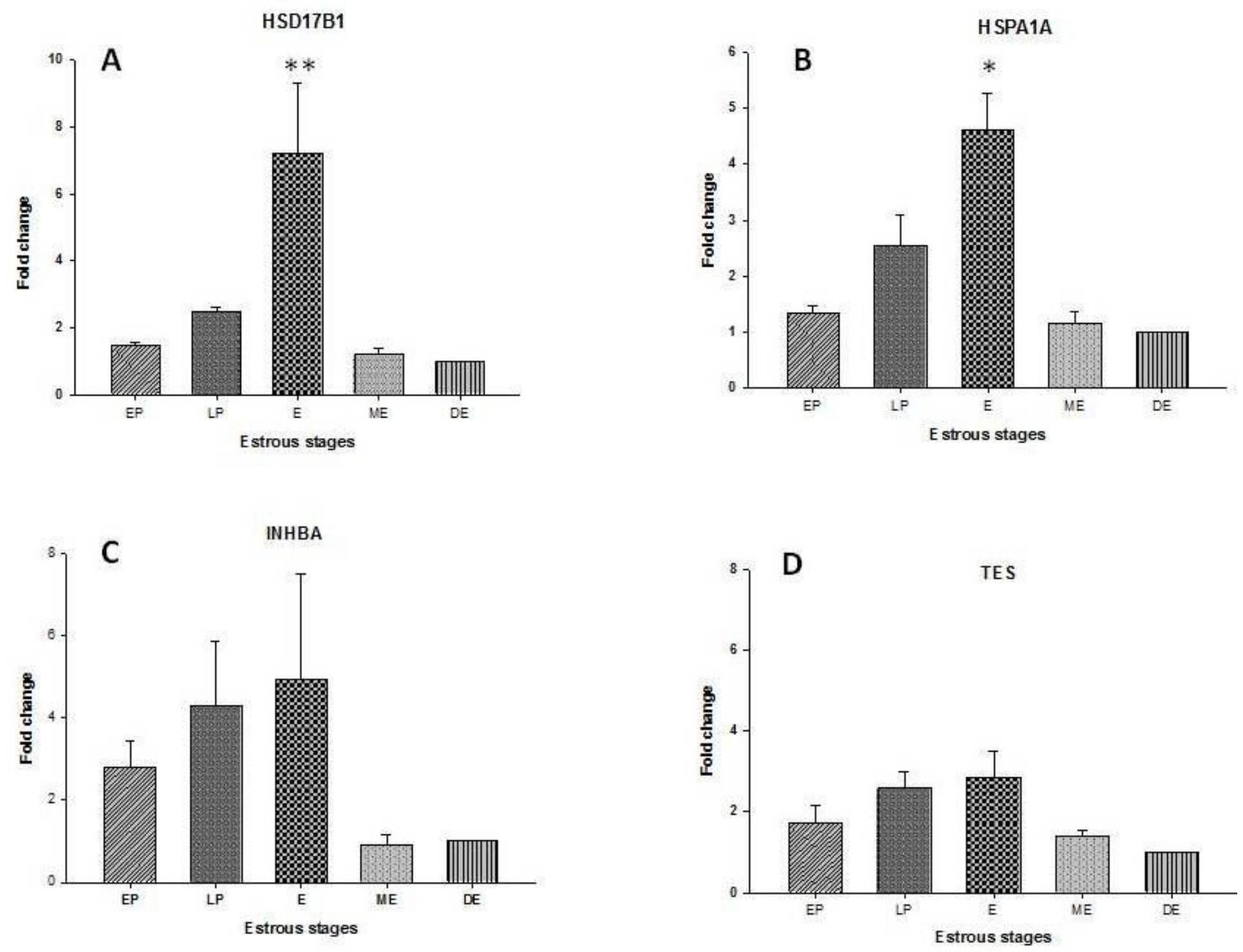

Figure 3

Quantitative real-time PCR analysis of (A) HSD17B1, (B) HSPA1A, (C) INHBA and (D) TES transcripts in saliva of pluriparous buffaloes during early proestrus (EP), late proestrus (LP), estrus (E), metestrus (ME) and diestrus (DE) stages. Each bar represents the mean \pm SE of gene expression data ${ }^{*} P<0.01, * \star P<0.001$ 


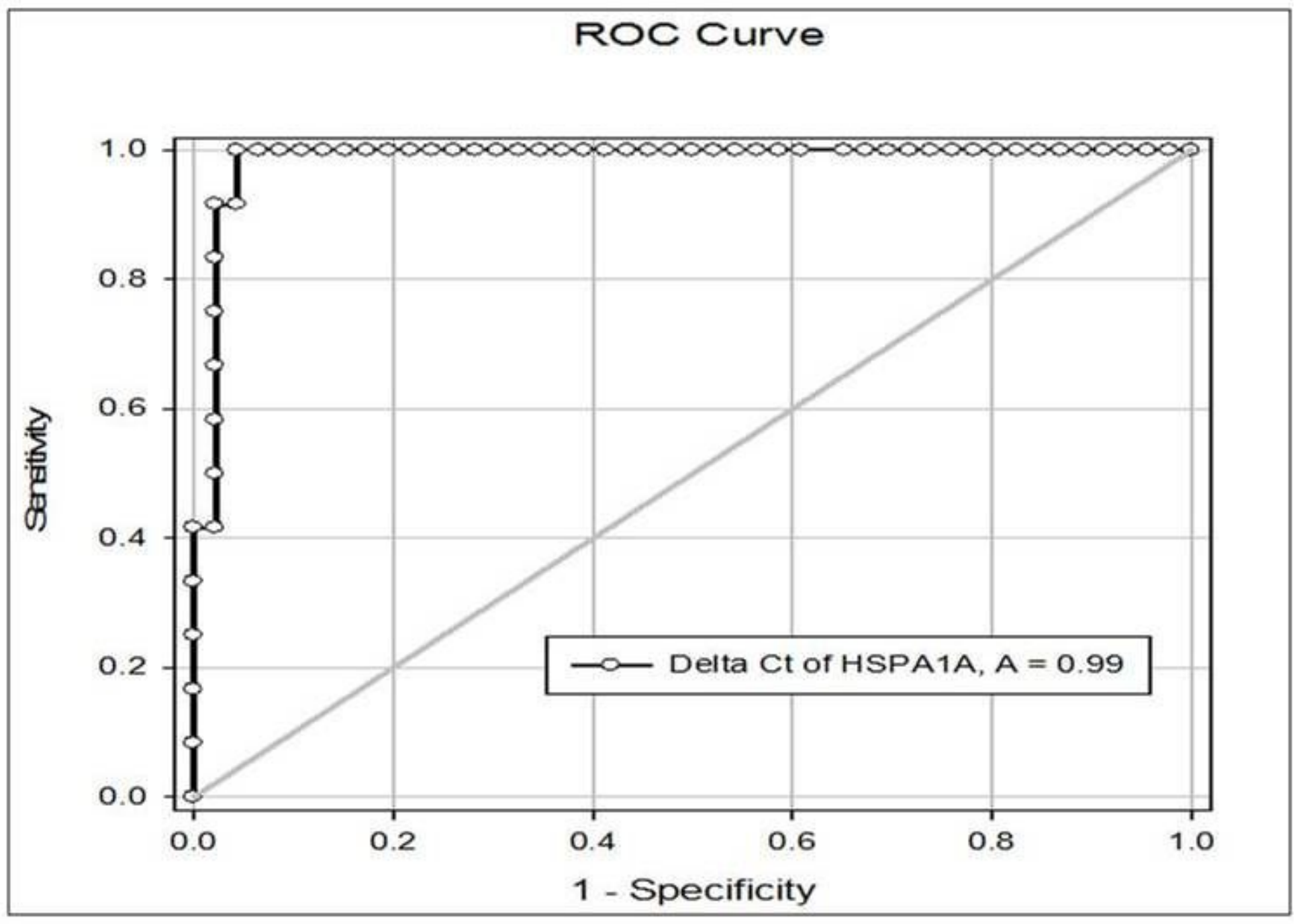

Figure 4

Receiver operating characteristic (ROC) curve analysis of HSPA1A as an estrus biomarker 


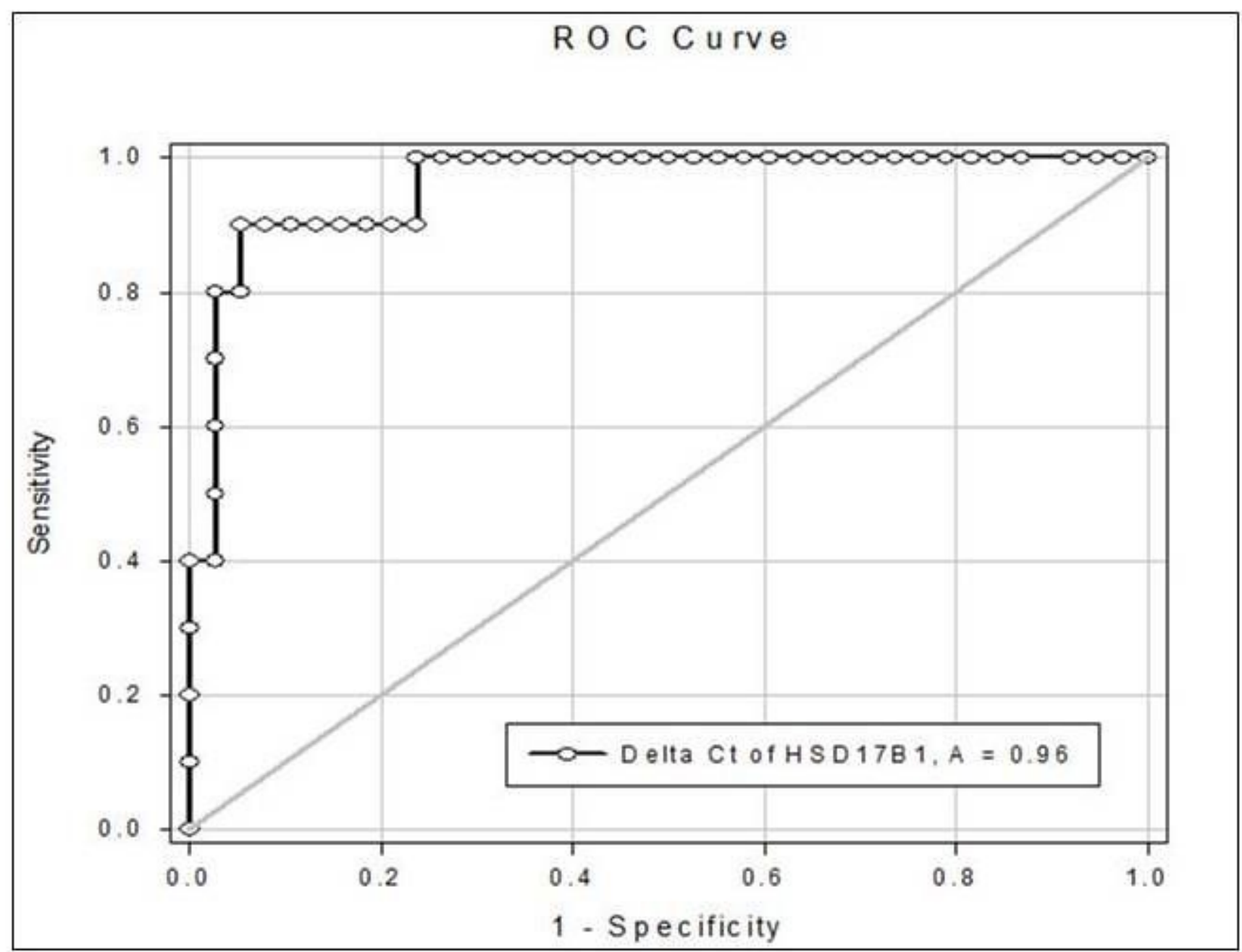

Figure 5

Receiver operating-characteristic (ROC) curve analysis of HSD17B1 as an estrus biomarker

\section{Supplementary Files}

This is a list of supplementary files associated with this preprint. Click to download.

- FigureS1.jpg

- Figures2.jpg

- FigureS3.jpg 